\title{
Freqüência de Mutação no Códon 12 do Gene K-ras no Carcinoma Ductal Invasivo de Mama
}

\author{
Frequency of Mutations at Codon 12 of the K-ras Gene in Invasive Ductal Breast Cancer
}

Sônia Maria Rolim Rosa Lima ${ }^{1}$, Sebastião Piatoํㅜ, Roberto Euzébio dos Santos ${ }^{1}$, Euclides Matheucci Junior ${ }^{2}$, Osmar Monte ${ }^{2}$

\begin{abstract}
RESUM0
Objetivo: pesquisar a freqüência de mutação pontual no códon 12 do gene $K$-ras, em espécimes cirúrgicos de pacientes portadoras de carcinoma ductal invasivo de mama.

Material e Métodos: foram utilizados cortes de 50 espécimes cirúrgicos incluidos em blocos de parafina, de pacientes portadoras de carcinoma ductal invasivo de mama, com graus histológicos II e III. Os cortes destinados ao estudo foram desparafinizados e submetidos a extração do DNA, por meio do emprego da proteinase K. Para a amplificação do fragmento a ser analisado, utilizou-se a reação em cadeia da polimerase, seguida por clivagem com o emprego de enzima de restrição de comprimento variável (RFLP). A verificação da presença de mutação nas amostras foi feita com o emprego de eletroforese em gel de agarose, com marcador de peso molecular "Ladder 123" (GIBCO-BRL), e a documentação dos resultados, mediante fotografia, utilizando-se luz ultravioleta transmitida.

Resultados: em cinco dos 50 carcinomas ductais invasivos de mama estudados (10\%) constatou-se a presença de mutação no códon 12 do gene K-ras, sendo todas elas polimórficas para esse caráter. As afetadas pelos tumores, que apresentavam a referida mutação, encontravam-se na pós-menopausa. Em quatro dos cinco casos em que se constatou a mutação, o grau histológico dos tumores era II e no caso restante III.
\end{abstract}

PALAVRAS-CHAVE: Mama: câncer. Reação em cadeia da polimerase. Oncogenes.

\section{Introdução}

Apesar dos avanços relacionados com o diagnóstico precoce do câncer de mama e de sua

\footnotetext{
${ }^{1}$ Departamento de Obstetrícia e Ginecologia

2 Departamento de Ciências Fisiológicas (Laboratório de Biologia Molecular)

Faculdade de Ciências Médicas da Santa Casa de São Paulo Correspondência:

Sônia Maria Rolim Rosa Lima

Rua Baltazar da Veiga 301, apto 81

04510-000 - São Paulo - SP
}

terapêutica, não se tem conseguido impacto significativo em relação à sobrevida ${ }^{8,20}$.

Tendo em vista que estudos experimentais têm demonstrado ser o câncer doença genética, resultante de alterações do ácido desoxirribonucléico $(\mathrm{DNA})^{5,14}$, as atenções em relação à carcinogênese mamária têm-se voltado para eventuais modificações do genoma, em particular as mutações pontuais de protooncogenes ${ }^{1,2,4,11}$.

A ocorrência de mutações pode ser incrementada quando certos agentes, conhecidos como mutagênicos, agem sobre DNA celular. As 
alterações eventualmente ocasionadas pelos mesmos são denominadas mutações induzidas. A maioria dos agentes possui a capacidade de atuar ocasionando modificações em bases específicas ou tornando-se incorporados ao ácido nucléico. $\mathrm{Na}$ carcinogênese em geral e em particular nas fases de iniciação, promoção e progressão do câncer mamário, radiações ionizantes e certos agentes quimicos têm sido incriminados como responsáveis por mutações induzidas ${ }^{10,16,21}$.

Com o advento de técnicas laboratoriais do DNA recombinante, abriram-se novas e revolucionárias perspectivas no estudo da identificação de mutações de proto-oncogenes. Dentre essas técnicas, cumpre destacar a reação em cadeia da polimerase (PCR), que foi idealizada por Kary Mullis, em 1984, e apresentada pela primeira vez à "American Society of Human Genetics", no ano de $1985^{29}$.

No que se refere à detecção da freqüência de mutações pontuais no códon 12 do gene K-ras na carcinogênese mamária, mediante utilização da PCR, existem poucos relatos na literatura internacional ${ }^{9,23,24}$, e nenhum em nosso meio.

\section{Material e Métodos}

O material utilizado no presente estudo consistiu de cortes com $8 \mu$ de espessura provenientes de 50 espécimes cirúrgicos de mulheres portadoras de carcinoma ductal invasivo de mama, incluídas em blocos de parafina. Para a determinação do grau histológico dos tumores, adotaram-se os critérios estabelecidos por Elston e Ellis ${ }^{13}$.

Entre as 50 pacientes estudadas, 33 (66\%) apresentavam-se na pós-menopausa. Em relação ao grau histológico dos tumores, 35 (70\%) eram grau II e os 15 (30\%) restantes, grau III.

Para a desparafinização dos dois cortes de cada espécime, foram colocados antes em tubo de Eppendorfde 1,5ml, ao qual foi: (a) adicionado $1 \mathrm{ml}$ de xileno em cada tubo, seguido de homogeneização a temperatura ambiente por 15 minutos; (b) centrifugação a 12.000 rotações por minuto (rpm), por três minutos; (c) remoção do xileno de cada amostra com pipeta Pasteur, tomando-se cuidado especial para evitar perdas de tecidos; (d) repetição dos passos a, b e c; (e) adição de aproximadamente $0,5 \mathrm{ml}$ de etanol $100 \%$ a cada tubo e nova homogeneização por inversão; (f) centrifugação a $12.000 \mathrm{rpm}$, por seis minutos; (g) remoção do etanol com pipeta Pasteur; (h) repetição dos passos e, f, g; e (i) secagem das amostras, até que o etanol tenha evaporado completamente, mantendo os tubos abertos e colocando-os cuidadosamente em uma placa de aquecimento a $37^{\circ} \mathrm{C}$, por quinze minutos ${ }^{17}$.

A extração do DNA dos cortes desparafinizados foi feita através da digestão do tecido, com emprego da proteinase $\mathrm{K}$, obedecendo aos seguintes passos: (a) adição às amostras de $100 \mu 1$ de tampão de digestão [10 mM Tris- $\mathrm{HCl}(\mathrm{pH} 8,0)$, $0,25 \mathrm{mM}$ de ácido etilenodiaminotetracético (EDTA, pH 8,0), 0,5\% de dodecilsulfato de sódio (SDS) e $100 \mathrm{mM}$ de $\mathrm{NaCl}$ ], contendo $200 \mu \mathrm{g} / \mathrm{ml} \mathrm{de}$ proteinase $\mathrm{K}$ (Merck); (b) incubação a $37^{\circ} \mathrm{C}$, por 16 horas; (c) incubação a $95^{\circ} \mathrm{C}$, por dez minutos, para inativar a proteinase K. Evitou-se aquecimento por mais de dez minutos, com a finalidade de manter a integridade do DNA; (d) adição de $10 \mu 1$ de cloreto de lítio $3 \mathrm{M}$, homogeneização por inversão e centrifugação a $12.000 \mathrm{rpm}$, por dez minutos; (e) transferência do sobrenadante para tubo novo; (f) adição de $500 \mu 1$ de etanol a 100\% e homogeneização por inversão e centrifugação a 13.000 rpm, por dez minutos; (g) descarte do etanol, adição de $500 \mu \mathrm{l}$ de etanol a 70\%, homogeneização por inversão e centrifugação a $13.000 \mathrm{rpm}$, por dez minutos; (h) secagem em banho seco a $37^{\circ} \mathrm{C}$, por 15 minutos; (i) ressuspensão do precipitado em $50 \mu \mathrm{l}$ de T.E. [10 mM de Tris $\mathrm{HCl} \mathrm{pH}$ 7,5 (Tris EDTA), $1 \mathrm{mM}$ de EDTA, pH 8,0]; e (j) manutenção das amostras a $-20^{\circ} \mathrm{C}$.

A reação em cadeia da polimerase (PCR) e a análise do polimorfismo do fragmento de comprimento variável obtido por clivagem com enzima de restrição (RFLP) foram efetuadas em 2 estágios. Numa primeira PCR, que teve como finalidade a amplificação de região específica de 157 pares de bases, contendo o códon 12 do gene $\mathrm{K}$-ras, utilizaram-se os oligonucleotídeos A e B, com suas respectivas bases com erro de pareamento (primers mismatches) sublinhadas na freqüência abaixo, idealizadas por Jiang et al. ${ }^{18}$ :

\section{A - 5' ACT GAA TAT AAA CTT GTG GTA GTT GGA $\underline{C} C T$ 3' \\ B - 5' TCA AAG AAT GGT CCT GGA CC 3'}

Seguindo as condições sugeridas pelo fabricante (Promega), a PCR foi realizada com volume final de $25 \mu$, contendo: $25 \mathrm{ng}$ de DNA (1 a $10 \mu 1$, após ressuspensão em $50 \mu 1$ de T.E.); quatro unidades de Taq DNA-polimerase; 50 pmoles de cada primer, $50 \mu 1$ de cada desoxirribonucleotídeo trifosfato (dATP, dCTP, dGTP, dTTP) a 1,25 mM cada; e 2,0 mM MgCl, $60 \mathrm{mM} \mathrm{KCl}$; e $10 \mathrm{mM}$ Tris$\mathrm{HCl}(\mathrm{pH} 8,8)$. As amostras foram então submetidas a amplificação por 12 ciclos, sendo em cada ciclo utilizadas temperaturas de $96^{\circ} \mathrm{C}$ (um minuto), $55^{\circ} \mathrm{C}$ (um minuto) e $72^{\circ} \mathrm{C}$ (meio minuto). Um controle 
negativo (sem DNA), com água destilada, foi empregado em cada ensaio. Após a PCR, os produtos obtidos foram submetidos a digestão enzimática com $10 \mathrm{U}$ de $M v a I$, por incubação por quatro horas a $37^{\circ} \mathrm{C}$, numa reação final de $25 \mu \mathrm{l}$, em tampão 1x (20 mM Tris-HCl, pH 8,5; $10 \mathrm{mM}$ $\mathrm{MgCl}_{2}, 1 \mathrm{mM}$ ditiotreitol, $100 \mathrm{mM} \mathrm{KCl}$ ), de acordo com as especificações do fabricante (Amersham).

Com vistas a aumentar a sensibilidade para a detecção de mutações do gene K-ras utilizou-se o aprimoramento da técnica da PCR proposto por Levi et al. ${ }^{19}$, que consistiu na realização de segunda PCR. Os primers mismatches A e C utilizados para amplificação do produto da primeira PCR, já digerido com $M v a I$, foram:

\section{A - 5' ACT GAA TAT AAA CTT GTG GTA GTT GGA $\underline{\text { CCT }} 3$ \\ C - 5' TAA TAT GTC GAC TAA AAC AAG TTT ACC TC 3'}

Do produto de digestão da primeira PCR, utilizou-se $1 \mu 1$, para a prática da segunda amplificação. Esta foi realizada por 25 ciclos e foi seguida de nova digestão enzimática por MvaI.

Completada a amplificação, estudaram-se $5 \mu 1$ de cada amostra, pela eletroforese em gel de agarose $0,8 \%$, com Tris-borato EDTA (TBE) 1x, juntamente com $1 \mu 1$ de tampão de amostra $6 x$ $(0,25 \%$ azul de bromofenol, 25\% xileno cianol e 30\% glicerol em $\mathrm{H}_{2} \mathrm{O}$ ), em placa do gel $0,8 \%$, contendo $0,5 \mathrm{mg} / \mathrm{ml}$ de brometo de etídio. Estas amostras foram colocadas em uma extremidade do gel e submetidas a eletroforese por 30 minutos, a 80 volts. A composição da solução padrão de TBE $5 x$ por litro é: $54 \mathrm{~g}$ de Tris base, 27,5 g de ácido bórico e $20 \mathrm{ml}$ de EDTA 0,5M (pH 8,0).

Para verificação da presença ou ausência de mutação em cada amostra estudada, foram utilizados marcadores de peso molecular "Ladder 123" (GIBCOBRL), aplicados nas extremidades de cada gel. Estes consistiram de segmentos com números de pares de base (pb) previamente conhecidos (123 pb, 246 pb,.... $3075 \mathrm{pb})$, que correram em paralelo nas margens laterais da placa.

A documentação dos resultados foi feita com a utilização de luz ultra-violeta transmitida e fotografia do gel de agarose, na qual foi utilizado filme Polaroid tipo 667 (ASA 3000).

\section{Resultados}

Em cinco dos 50 espécimes cirúrgicos de carcinoma ductal invasivo de mama estudados $(10 \%)$ constatou-se a presença de mutação pontual no códon 12 do gene K-ras.

$\mathrm{Na}$ Tabela 1 apresentamos a idade das pacientes, a idade em que ocorreu a menopausa das mesmas e o grau histológico dos cinco tumores de mama, nos quais foram detectadas as referidas mutações.

Tabela 1 - Idade e época da menopausa das pacientes e grau histológico dos tumores, nos casos em que se detectou mutação no códon 12 do gene K-ras.

\begin{tabular}{cccccc}
\hline No $^{0}$ & NOME & $\begin{array}{c}\text { REGISTRO } \\
\text { GERAL }\end{array}$ & IDADE & MENOPAUSA & $\begin{array}{c}\text { GRÁU } \\
\text { HISTOLÓGICO }\end{array}$ \\
\hline 01 & MRMT & 253094 & 54 & 47 & II \\
02 & AAM & 255316 & 72 & 57 & II \\
03 & AGO & 255515 & 59 & 58 & III \\
04 & MVLN & 256851 & 71 & 40 & II \\
05 & ALCC & 1032316 & 74 & 54 & II \\
\hline
\end{tabular}

Na Figura 1 apresentamos foto da placa de gel de agarose, na qual estão quatro dos cinco casos em que ocorreu mutação no códon 12 do gene Kras. Como se pode observar, os fragmentos em que ocorreu a mutação apresentam-se polimórficos.

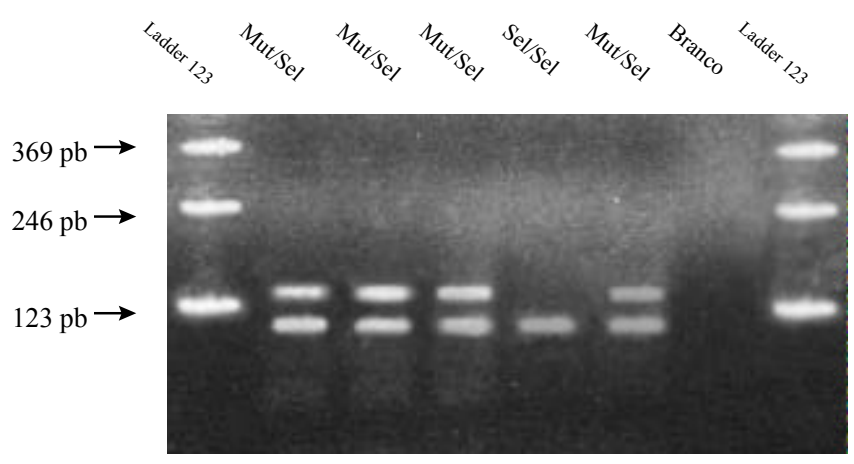

Figura 1 - Foto de gel de agarose, na qual se pode observar: nas colunas 1 e 8 (Ladder 123), marcador de peso molecular conhecido; na 7, o controle (branco); na 5 (Sel/Sel), amostra do gene selvagem; e nas 2, 3, 4 e 6 (Mut/Sel), as amostras dos genes mutantes encontradas em quatro de nossos casos.

\section{Discussão}

Desde o ano de 1982, época em que foram realizadas as primeiras investigações acerca da participação dos genes ras ativados no desenvolvimento de tumores humanos, grande número de relatos surgiram na literatura a respeito do tema ${ }^{2,7,12,22,27}$.

Como bem relatam Deyo et al. ${ }^{12}$, os genes ras colocam-se atualmente entre as moléculas mais estudadas nas ciências biomédicas. $\mathrm{Na}$ opinião destes e de outros autores, as recentes descobertas começam a proporcionar esclarecimentos acerca dos fluxos ascendente e 
descendente da intrincada via de transdução de sinais, na qual as proteínas codificadas pelos genes ras ocupam papel central ${ }^{1,2,7,12,15}$.

As mutações pontuais nos códons 12, 13 e 61 dos proto-oncogenes ras fazem com que os mesmos se transformem em oncogenes. Tais oncogenes são definidos como genes ras alterados, que podem transformar a linhagem celular de camundongos NIH/3T3 em células tumorais ${ }^{23,28}$. Assim transformados, os genes ras podem ocasionar alterações da atividade GTPase da p21, capazes de impedir o desligamento entre a mesma e a GTP2 Nesta situação, a perda da atividade GTPase resulta em permanente ligação da GTP à proteína Ras. Como decorrência, esta proteína permanece em sua configuração ativa, enviando os sinais contínuos de transdução para o crescimento e diferenciação celular ${ }^{6}$. A clonagem celular persistente que resulta desta alteração, pode ter participação decisiva nas fases da carcinogênese de determinado tecido. Segundo Rodenhuis et al. ${ }^{26}$, fortes evidências sugerem que mutações no proto-oncogene K-ras são eventos iniciais na carcinogênese mamária.

Os conhecimentos acerca das mutações pontuais dos proto-oncogenes foram incrementados após o advento da técnica da PCR. A utilização de primers contendo mismatches, criados por Jiang et al. ${ }^{18}$, constituiu artificio de extraordinária eficácia para a detecção de mutações pontuais no códon 12 do proto-oncogene $\mathrm{K}$-ras. Cabe assinalar ainda, que a realização de segunda PCR, proposta por Levi et al. ${ }^{19}$, aumentou a sensibilidade do método para a detecção das referidas mutações.

Pela análise da literatura, pode-se constatar que as investigações relacionadas com mutação pontual do gene K-ras em câncer mamário mostram resultados díspares, que vão desde a ausência da mesma até taxas em torno de $10 \%{ }^{12}$. Em estudo de 40 casos de câncer primário de mama, nos quais utilizaram a técnica original da PCR, Rochlitz et al. ${ }^{25}$ encontraram a referida mutação em apenas dois (5\%) dos mesmos.

A presente investigação, que foi dirigida especificamente ao carcinoma ductal invasivo de mama, com a utilização de primers mismatches idealizados por Jiang et al. ${ }^{18}$ e de dupla PCR, proposta por Levi et al. ${ }^{19}$, revelou incidência de mutação pontual do proto-oncogene K-ras em 10\% dos tumores. Acreditamos que esta taxa mais elevada da freqüência de mutação em nosso material, quando comparada com a média dos dados referidos na literatura, possa estar relacionada com maior sensibilidade da metodologia laboratorial utilizada.

No nosso estudo verificamos que todas as pacientes, nas quais o carcinoma mamário apresentou mutação pontual, encontravam-se na pós-menopausa. Por se tratar de número reduzido de casos, entendemos que novas pesquisas devam ser realizadas para melhor ajuizamento deste fato.
No que se relaciona ao grau histológico dos tumores, igualmente achamos que são necessários estudos com maior casuística, para adequada correlação entre o mesmo e a freqüência de mutação do gene K-ras.

Dentro do cenário atual, acreditamos que o presente trabalho constitui uma contribuição para o futuro entendimento dos intrincados mecanismos responsáveis pelas diferentes fases do desenvolvimento do câncer de mama, assim como de aspectos relacionados com a prevenção primária, o prognóstico e a terapêutica desta neoplasia. Para tanto, entendemos que se torna necessário estudo prospectivo de um número maior de casos, nos quais se consiga detectar a mutação pontual investigada no presente estudo.

Ao termo desta discussão, que se baseou nos resultados de alguns dos exaustivos esforços desenvolvidos pelos cientistas para desvendar aspectos do complexo mecanismo responsável pelo surgimento do câncer de mama, achamos de maior propriedade as recentes afirmativas de Barros e Pinotti ${ }^{3}$. Segundo estes autores, "o conhecimento sobre a carcinogênese mamária hoje disponivel, que se enriquece dia a dia, ainda é representado apenas por fragmentos de um amplo processo, lembrando peças de um verdadeiro quebra-cabeças. Esta área tem despertado com muita ênfase o interesse de pesquisadores, porque à medida que surgem novos avanços, paralelamente se abrem novas perspectivas em termos de prevenção primária, detecção precoce e terapêutica do câncer de mama".

\section{SUMMARY}

Purpose: the frequency of point mutation at codon 12 of the $K$-ras gene was determined in paraffin blocks of surgical specimens from patients who had ductal invasive breast cancer.

Material and Methods: Fifty surgical specimens blocked in paraffin from patients with ductal invasive breast cancer, with histological degree II and III, were used. The polymerase chain reaction (PCR) was used for amplification of DNA fragments studied. The material cleavage was obtained with restriction fragment length polymorphisms (RFLP). The electrophoresis in agarose gel, with Ladder 123 (GIBCO$B R L)$ marker, was employed to verify if some mutation had occurred. The results were shown using ultraviolet beam and recorded by photos.

Results: mutations at codon 12 of $K$-ras gene were found in five samples (10\%) and all of them were polymorphic for this caracter. The five patients whose tumors expressed mutation were in the postmenopausal period. Four patientes had tumors of histological degree II and one, III.

KEY WORDS: Breast neoplasms. Polymerase chain reaction. Oncogenes. 


\section{Referências}

1. Alberts B, Bray D, Lewis J, Raff M, Roberts K, Watson JD. Cancer. In: Alberts B, Bray D, Lewis J, Raff M, Roberts K, Watson JD, editores. Biologia Molecular da Célula. $3^{\mathrm{a}}$ ed. Porto Alegre: Artes Médicas; 1997. p.1255-91.

2. Barbacid M. Ras genes. Annu Rev Biochem 1987; 56:779827.

3. Barros ACSD, Pinotti JA. Bases da carcinogênese mamária. In: Dias EN, Silva HMS, Barros ACSD, Figueira Filho ASS, editores. Controvérsias em Mastologia. São Paulo: Escola Brasileira de Mastologia; 1996. p.69-82.

4. Bishop JM. The molecular genetics of cancer. Science 1987; 235:305-11.

5. Bishop JM. Molecular themes in oncogenesis. Cell 1991; 64:235-48.

6. Bortner DM, Langer SJ, Ostrowski MC. Non-nuclear oncogenes and the regulation of gene expression in transformed cells. Crit Rev Oncogenes 1993; 4:137-60.

7. Bos JL. Ras oncogenes in human cancer: a review. Cancer Res 1989; 49:4682-9.

8. Brinton LA, Devesa SS. Etiology and pathogenesis of breast cancer: epidemiologic factors. In: Harris JR, Lippman, ME, Morrow, HS editores. Diseases of the Breast. Philadelphia: Lippincott; 1996. p.159-219.

9. Capella G, Cronauer-Mitra S, Pienado MA, Perucho M. Frequency and spectrum of mutations at codons 12 and 13 of the c-K-ras gene in human tumors. Environ Health Perspect 1991; 93:125-31.

10.Carlson RW, Stockdale FE. The clinical biology of breast cancer. Ann Rev Med 1988; 39:453-64.

11.Cortner J, Vande Woude GF. Essentials of molecular biology. In: De Vita Junior, VT; Hellman S, Rosenberg SA, editores. Principles \& Practice of Oncology. 5nd ed. Philadelphia: Lippincott-Raven; 1997. p.3-33.

12.Deyo J, Berger D, Tainsky MA. The ras oncogene: from basic mechanisms to therapeutic intervention. In: Freireich EJ, Stass SA editores. Molecular Basis of Oncology. Cambridge: Blackwell Science, 1995. p.63-100.

13.Elston CW, Ellis IO. Pathological prognostic factors in breast cancer.I. The value of histological grade in breast cancer: experience from a large study with long-term follow-up. Histopathology 1991;19:403-10.

14.Fearon ER, Vogelstein B. A genetic model for colorectal tumorigenesis. Cell 1990; 61:759-67.

15. Hall A. ras and GAP-Who's controlling whom? Cell 1990; 61:921-3.

16. Hall EJ. Etiology of cancer: physical factors. In: De Vita Junior VT, Hellman S, Rosenberg SA, editores. Principles \& Practice of Oncology. 5nd ed. Philadelphia: Lippincott-Raven; 1997. p.203-18.

17.Hruban RH, van Mansfeld AD, Offerhaus GJA, van Weering DH, Allison DC, Goodman,SN, et al. K-ras oncogene activation in adenocarcinoma of the human pancreas. A study of 82 carcinomas using a combination of mutant-enriched polymerase chain reaction analysis and allele-specific oligonucleotide hybridization. Am J Pathol 1993; 143:545-54.
18.Jiang W, Kahn SM, Guillem JG, Shih-Hsin L, Weinstein IB. Rapid detection of ras oncogenes in human tumours: applications to colon esophageal, and gastric cancer. Oncogene 1989; 4:923-8.

19.Levi S, Urbano-Ispizua A, Gill R, Thomas DM, Gibertson J, Foster C, Marshall CJ. Multiple K-ras codon 12 mutations in cholangiocarcionamas demonstrated with a sensitive polymerase chain reaction technique. Cancer Res 1991; 51:3497-502.

20.Miller BA, Feuer EJ, Hankey BF. Recent incidence trends for breast cancer in women and the relevance of early detection: an update. CA Cancer J Clin 1993; 43:27-41.

21.Murray RK. Cancer, oncogenes $\&$ fatores de crescimento. In Harper HA, editores. Bioquímica. $6^{\mathrm{a}}$ ed. São Paulo: Atheneu; 1990.p.647-60.

22.Parada LF, Tabin CJ, Shih C, Weinberg RA. Human EJ bladder carcinoma oncogene is homologue of Harvey sarcoma virus ras gene. Nature 1982; 297:474-8.

23.Perucho M, Peinado A, Velazquez A, Mok CH, Berkowitz RS. Molecular basis of gynecological oncology. In: International Meeting European Society of Gynecological Oncology. Barcelona: 1993.

24.Prosperi MT, Dupré G, Lidereau R, Goubin G. Point mutation at codon 12 of the Ki-ras gene in a primary breast carcinoma and the MDA-MB-134 human mammary carcinoma cell line. Cancer Lett 1990 $51: 169-74$

25.Rochlitz CF, Scott GK, Dodson JM, Liu E, Dollbaum C, Smith HS, et al. Incidence of activating ras oncogene mutations associated with primary and metastatic human breast cancer. Cancer Res 1989; 49:357-60.

26. Rodenhuis S, Top B, Klaver SG, Witvliet M, Maas RA, de Lange $M$, et al. Oncogenes and response prediction in human tumours. Annu Rep Neth Cancer Inst 1993; 78.

27. Russo J, Russo IH. Biological and molecular bases of mammary carcinogenesis. Lab Invest 1987; 57:11237.

28. Shih C, Padhy LC, Murray M, Weinberg RA. Transforming genes of carcinomas and neuroblastomas introduced into mouse fibroblast. Nature 1981; 290:261-4.

29. Templeton NS. The polymerase chain reaction: history, methods and applications. Diagn Mol Pathol 1992; $1: 58-72$

\section{Agradecimentos}

Ao Prof. Dr. Fausto Baracat, Diretor Clínico do Instituto do Câncer Arnaldo Vieira de Carvalho (IAVC), pelo fornecimento do material anátomopatológico, e ao Dr. Roberto A. Pinto Paes, patologista responsável pelo Serviço de Anatomia Patológica do IAVC, pela extrema gentileza e ajuda na seleção dos exames histopatológicos dos espécimes mamários. 